\title{
SYNTHESIS AND ANTIHYPERLIPIDEMIC ACTIVITY OF CERTAIN NICOTINIC ACID DERIVATIVES
}

\author{
Abdel Ghany A. El-Helby and Mohamed H. Abdel-Wahab* \\ Departments of Pharmaceutical Chemistry, and (Pharmacology and Toxicology)*, Faculty of \\ Pharmacy, Al-Azhar University, Cairo, Egypt

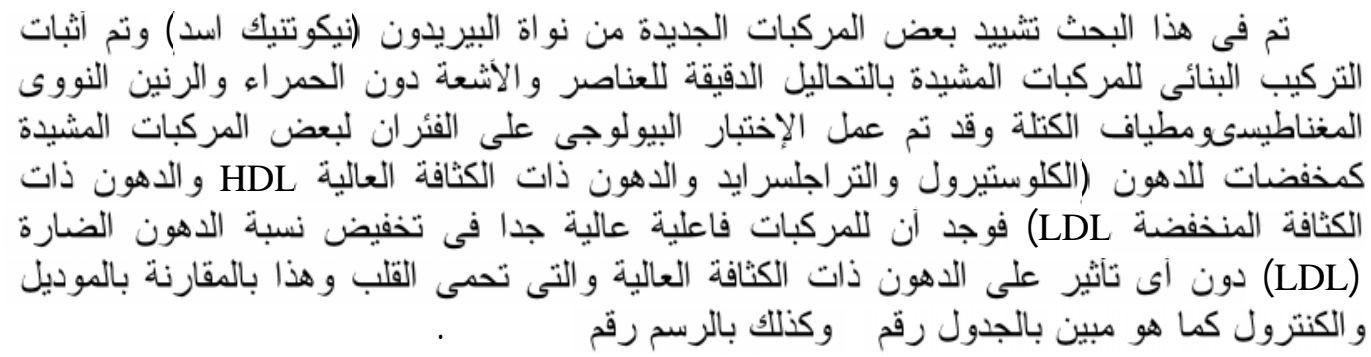

3-Ethoxycarbonyl-4,6-dimethyl-2(1H)-pyridone I was prepared and converted to the corresponding sodium salt II. The latter reacted with certain chloroacetanilides to afford the corresponding ethers III. In addition 3-cyano-4,6-dimethyl-2(1H)-pyridone $\mathbf{I V}$ was prepared and converted to the corresponding potassium salt $\boldsymbol{V}$ which was allowed to react with $\alpha$ chloroacetyl and $\beta$-chloropropionyl derivatives of certain aromatic amines to afford VI. Furthermore, IV was converted to 3-cyano-4,6-dimethyl pyridine-2-thione IX. Potassium salt of the latter upon reaction with $\alpha$-chloroacetyl and $\beta$-chloropropionyl derivatives of some aromatic amines gave the expected thioethers $\boldsymbol{X}$. Compounds $\boldsymbol{I I I}_{2}, \boldsymbol{V}_{4}, \boldsymbol{X}_{1}$ and $\boldsymbol{X}_{12}$ were selected for testing for antihyperlipidemic effect and revealed promising hypolipidemic effect on cholesterol, triglyceride, LDL and have no effect on HDL.

\section{INTRODUCTION}

Some new derivatives of nicotinonitrile and nicotinamide exhibited antihypertensive $\beta$ adrenergic bloking activity. ${ }^{1-3}$ Osman et $a l^{4}$ synthesized some derivatives of 3-ethoxycarbonyl-4,6-dimethyl-2(1H)-pyridone and evaluated them as antihyperlipidemic agents. Consequently, it was decided to synthesize certain new nicotinic acid derivatives for evaluation as antihyperlipidemic agents aiming to avoid drawbacks of the nicotic acid itself.

\section{EXPERIMENTAL}

All meting points were carried out on Geriffin melting point apparatus and are uncorrected. Elemental analysis were performed on $\mathrm{CHN}$ analyzer at the Microanalytical unit, Cairo University, Cairo, Egypt. The IR spectra were recorded on a Pye
Unicam SP-1000 IR spectrophotometer at Microanalytical Unit., Cairo University. ${ }^{1}$ HNMR spectra were recorded on a Joel 200 $\mathrm{MHz}$ spectrometer at Faculty of Science, Cairo, University, Cairo, Egypt. And Inova 400 CosyChem. buffalo edu. at the Natural Science Complexes, Buffalo, USA. Chemical values were expressed by $\delta$ values using TMS as internal standard. Mass spectra were performed on Hewlett Packard 5988 (70 ev) spectrometer at the Microanalytical Unit, Cairo, University.

The following non available intermediates were prepared according to reported procedures: 3-ethoxycarbonyl-4,6-dimethyl$2(1 \mathrm{H})$-pyridone $\mathbf{I}^{4,5}$ and its sodium salt $\mathbf{I I},{ }^{4,5} 3$ cyano-4,6-dimethyl $2(1 \mathrm{H})$ pyridone $\mathbf{I V}^{6,7}$ and its potassium salt, ${ }^{8}$ 2-chloro-3-cyano-4,6dimethyl-pyridone VII, ${ }^{4-7,9}$ chloroacetanilides and $\beta$-chloropropionoyl anilides. ${ }^{10}$ 
<smiles>CC(=O)CC(C)=O</smiles><smiles>CCOC(=O)CC#N</smiles><smiles>CCCCCCCO</smiles><smiles>CCOC(=O)c1c(C)cc(C)[nH]c1=O</smiles>

(I)<smiles>[R][X]c1cccc(NC(=O)CCl)c1</smiles>

DMF / $\Delta$<smiles>CCOC(=O)c1c(C)cc(C)nc1[O+]</smiles>

(II)
$\stackrel{+}{\mathrm{Na} /}$ ethanol absolute<smiles>[R]c1cccc(NC(=O)COc2nc(C)cc(C)c2C(=O)OCC)c1</smiles>

(III $1-7)$

$$
\begin{aligned}
& \text { (III } 1 \text {-7) } \\
& \mathrm{R}= \\
& \text { 1) } \mathrm{H} \\
& \text { 2) } 4-\mathrm{CH}_{3} \\
& \text { 3) } 4-\mathrm{Cl} \\
& \text { 4) 2,6-dichloro } \\
& \text { 5) } 4-\mathrm{Br} \\
& \text { 6) } 2-\mathrm{CO}_{2} \mathrm{CH}_{3} \\
& \text { 7) } 4-\mathrm{COOCH}_{3}
\end{aligned}
$$

\section{Scheme 1}


<smiles>CC(=O)CC(C)=O</smiles><smiles>Cc1cc(C)c(C#N)c(=O)[nH]1</smiles>

(IV)

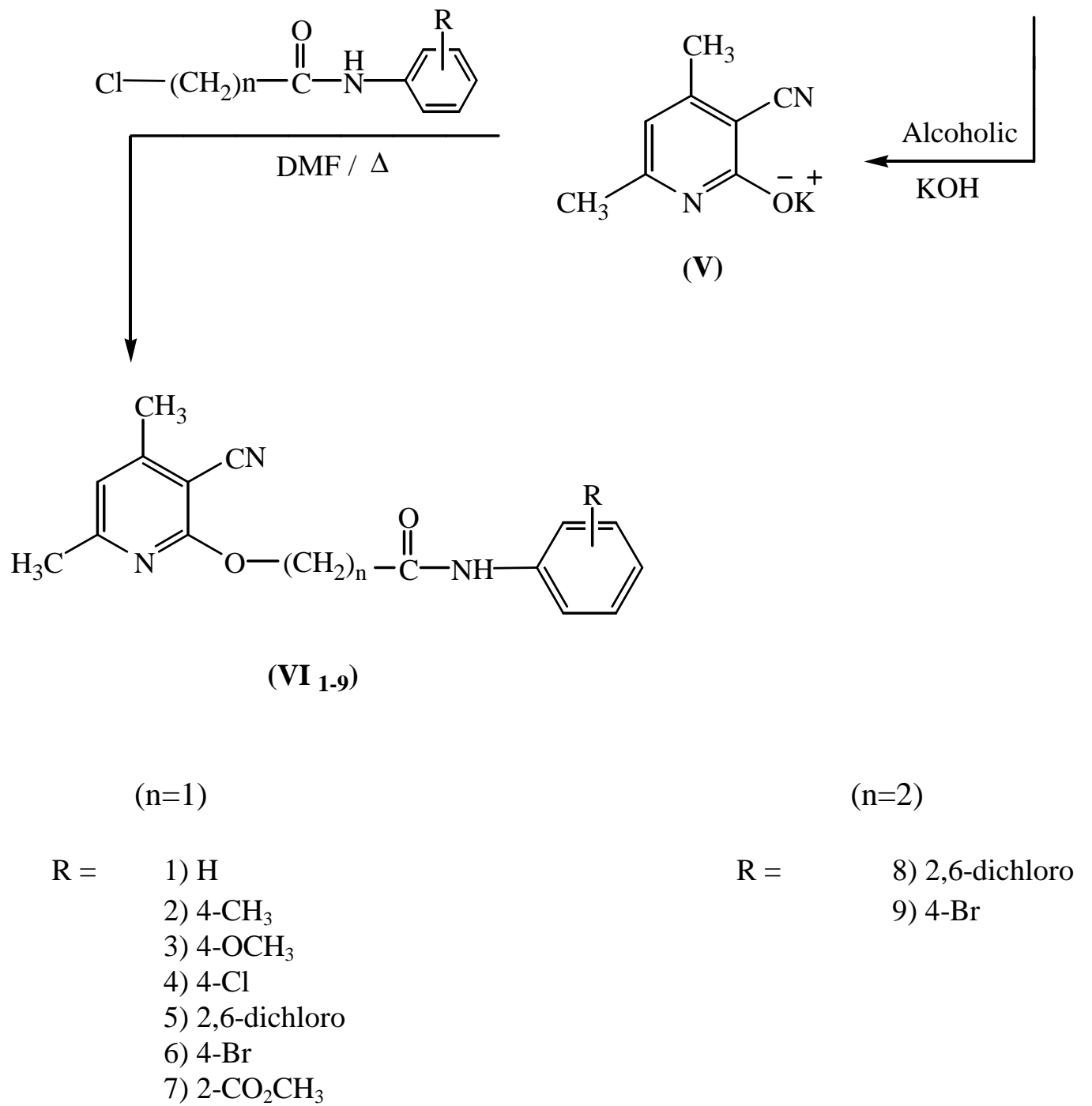

Scheme 2 
<smiles>Cc1cc(C)c(C#N)c(=O)[nH]1</smiles><smiles>[CH][C@H](C)C(=O)O</smiles>

(IV)<smiles>Cc1cc(C)c(C#N)c(Cl)n1</smiles><smiles>[R][X]c1ccccc1NC(=O)[In]CCl</smiles><smiles>[Y]c1nc(C)cc(C)c1C#N</smiles>

(IX)<smiles>Cc1cc(C)c(C#N)c(S)n1</smiles>

(VIII)<smiles>[R]c1cccc(NC(=O)CCCc2nc(C)cc(C)c2C#N)c1</smiles>

$\left(\mathrm{X}_{1-12}\right)$

$$
\begin{array}{ll}
\left(\mathrm{X}_{1-8}\right)(\mathrm{n}=1) \\
\mathrm{R}=\quad \text { 1) } \mathrm{H} \\
\text { 2) } 4-\mathrm{CH}_{3} \\
\text { 3) } 4-\mathrm{OCH}_{3} \\
\text { 4) } 4-\mathrm{Br} \\
\text { 5) } 4-\mathrm{Cl} \\
\text { 6) } 2,6-\text { dichloro } \\
\text { 7) } 2-\mathrm{CO}_{2} \mathrm{CH}_{3} \\
\text { 8) } 4-\mathrm{CO}_{2} \mathrm{CH}_{3}
\end{array}
$$

$$
\left(\mathrm{X}_{9-12}\right)(\mathrm{n}=2)
$$$$
\mathrm{R}=
$$$$
\text { 9) } \mathrm{H}
$$$$
\text { 10) } 4-\mathrm{CH}_{3}-\mathrm{Br}
$$$$
\text { 11) } 4-\mathrm{Br}
$$

12) 2,6-dichloro

Scheme 3 


\section{3-Ethoxycarbonyl-4,6-dimethyl-2- substituted pyridines III $_{1-7}$}

A mixture of 3-ethoxycarbonyl-4,6dimethyl-2-pyridone sodium salt II $2.17 \mathrm{~g}(0.01$ mole), chloroacetanilides $1.7 \mathrm{~g}$ (0.01 mole) and dimethylformamide $20 \mathrm{ml}$ was heated on waterbath for $3 \mathrm{hr}$, the reaction mixture was cooled, poured onto water. The solid so obtained was filtered, washed with water and crystallized from ethanol (Table 1).

\section{Potassium salt of 3-cyano-4,6-dimethyl- 2(1H)-pyridone $\mathrm{V}$}

3-Cyano-4,6-dimethyl-2(1H)-pyridone IV $1.48 \mathrm{~g}(0.01 \mathrm{~mole})$ was treated with alcoholic solution of potassium hydroxide (0.01 mole) until dissolved, the solution was stirred for 30 min, the potassium salt of the target compound was separated as solid product, filtered, washed several times with absolute ethanol and then dried.

m.p, 265-6 $6^{\circ}$ as reported; Yield, $1.86 \mathrm{~g}$ (100\%) as reported..$^{8}$

\section{3-Cyano-4,6-dimethyl-2-substituted pyridines $\mathrm{VI}_{1-9}$}

A mixture of potassium salt $\mathbf{V} 1.86 \mathrm{~g}(0.01$ mole), $\alpha$-chloroacetyl or $\beta$-chloropropionyl aromatic amines (0.01 mole) and dimethyl formamide $(20 \mathrm{ml})$ was heated on water-bath for $3 \mathrm{hr}$, the reaction mixture was cooled, poured onto water, the precipitate was filtered, washed with water and recrystallized from ethanol (Table 2).

\section{3-Cyano-4,6-dimethylpyridine-2-thione VIII}

A mixture of 2-chloro-3-cyano-4,6dimethylpyridine VII $1.66 \mathrm{~g}$ (0.01 mole) and thiourea $1.52 \mathrm{~g}$ (0.02 mole) was heated under reflux in absolute ethanol $(50 \mathrm{ml})$ for $4 \mathrm{hr}$. The formed yellow crystals was filtered while hot and washed with ethanol and crystallized from ethanol.

Analysis of $\mathrm{C}_{8} \mathrm{H}_{8} \mathrm{~N}_{2} \mathrm{~S}$, M.Wt., 164.23; m.p, 285$6^{\circ}$; yield $1.4 \mathrm{~g}(85 \%)$.

$\begin{array}{cccc} & \mathrm{C} \% & \mathrm{H} \% & \mathrm{~N} \% \\ \text { Calcd. } & 58.51 & 4.91 & 17.06 \\ \text { Found } & 58.32 & 5.00 & 16.95\end{array}$

Potassium 3-cyano-4,6-dimethylpyridine-2thiolate IX

3-Cyano-4,6-dimethylpyridine-2-thione VIII $1.64 \mathrm{~g}$ (0.01 mole) was dissolved in alcholic solution of $\mathrm{KOH} 0.056 \mathrm{~g}$ (0.01 mole) with stirring, the potassium salt of the target compound was immediately precipitated washed with ethanol then dried.

m.p, 280-1 ${ }^{\circ}$; yield, (2.02 g) 100\%.

\section{3-Cyano-4,6-dimethyl-2-(substitutedthio) pyridines $\mathrm{X}_{1-12}$}

A mixture of the potassium salt IX $2.02 \mathrm{~g}$ (0.01 mole) and $\alpha$-chloroacetyl or $\beta$ chloropropionyl aromatic amines (0.01 mole) was heated on water-bath for $4 \mathrm{hr}$ in DMF (20 $\mathrm{ml})$. The reaction mixture was cooled, poured onto water, the solid so obtained was filtered and crystallized from ethanol (Table 3).

\section{RESULT AND DISCUSSION}

Condensation of acetylacetone and ethyl cyanoacetate in absolute ethanol containing triethylamine (TEA) afforded 3-ethoxycarbonyl-4,6-dimethyl-2(1H)-pyridone $\mathbf{I}^{4,5}$ The latter upon reaction with $\mathrm{NaOC}_{2} \mathrm{H}_{5}$ afforded its sodium salt ${ }^{4}$ II. Reaction of II with certain chloroacetanilides afforded the corresponding ethers, ethyl 3-ethoxycarbonyl-4,6-dimethyl-2substitutedpyridines III $_{\text {1-7. }}$. IR spectra of such compounds showed absorption at 1719-1735 $\mathrm{cm}^{-1}$ and $3380 \mathrm{~cm}^{-1}$ for the ester carbonyl and $\mathrm{NH}$ absorption bands respectively. The amide carbonyls of these compounds exhibited bands at 1643-1637 $\mathrm{cm}^{-1}$. The ${ }^{1}$ HNMR spectra showed the presence of methylene group at $\delta$ $4.88-4.92 \mathrm{ppm}$. The NH proton appeared at $\delta$ 9.65- $10.20 \mathrm{ppm}$. Reaction of acetylacetone and cyanoacetamide in the presence of TEA afforded 3-cyano-4,6-dimethyl-2(1H)-pyridone IV, which was converted into the corresponding potassium salt $\mathbf{V}$ through the reaction with alcoholic $\mathrm{KOH}^{8}{ }^{8}$ The potassium salt $\mathbf{V}^{8}$ was allowed to react with $\alpha$ chloroacetyl and $\beta$-chloropropionyl derivatives of certain aromatic amines to afforded 3-cyano4,6-dimethyl-2-substituted pyridines $\mathbf{V I}_{\mathbf{1 - 9}}$. IR spectra of such compounds showed the absorption band at $3270 \mathrm{~cm}^{-1}$ for the $\mathrm{NH}$ 
Table 1: 3-Ethoxycarbonyl-4,6-dimethyl-2-substituted pyridines III $_{\mathbf{1 - 7}}$.<smiles>[R][I-]1C=CC=C(NC(=O)COc2nc(C)cc(C)c2C(=O)OCC)C1</smiles>

\begin{tabular}{|c|c|c|c|c|c|c|c|}
\hline \multirow{2}{*}{$\begin{array}{l}\text { Comp. } \\
\text { No. }\end{array}$} & \multirow{2}{*}{$\mathrm{R}$} & \multirow{2}{*}{ M.P, } & \multirow{2}{*}{$\begin{array}{c}\text { Yield } \\
\%\end{array}$} & \multirow{2}{*}{$\begin{array}{c}\text { Molecular formula } \\
\text { M.Wt }\end{array}$} & \multicolumn{3}{|c|}{ Elemental analyses } \\
\hline & & & & & $\%$ & Calcd. & Found \\
\hline \multirow{3}{*}{ IIII $_{1}$} & \multirow{3}{*}{$\mathrm{H}$} & \multirow{3}{*}{$140-1$} & \multirow{3}{*}{72} & \multirow{3}{*}{$\begin{array}{c}\mathrm{C}_{18} \mathrm{H}_{20} \mathrm{~N}_{2} \mathrm{O}_{4} \\
328.36\end{array}$} & $\mathrm{C}$ & 65.84 & 66.10 \\
\hline & & & & & $\mathrm{H}$ & 6.14 & 6.40 \\
\hline & & & & & $\mathrm{N}$ & 8.53 & 8.56 \\
\hline \multirow{3}{*}{$\mathbf{I I I}_{2}$} & \multirow{3}{*}{$4-\mathrm{CH}_{3}$} & \multirow{3}{*}{$165-6$} & \multirow{3}{*}{75} & \multirow{3}{*}{$\begin{array}{c}\mathrm{C}_{19} \mathrm{H}_{22} \mathrm{~N}_{2} \mathrm{O}_{4} \\
342.39\end{array}$} & $\mathrm{C}$ & 66.65 & 66.30 \\
\hline & & & & & $\mathrm{H}$ & 6.46 & 6.70 \\
\hline & & & & & $\mathrm{N}$ & 8.18 & 8.13 \\
\hline \multirow{3}{*}{$\mathrm{III}_{3}$} & \multirow{3}{*}{$4-(\mathrm{Cl})$} & \multirow{3}{*}{$195-6$} & \multirow{3}{*}{71} & \multirow{3}{*}{$\begin{array}{c}\mathrm{C}_{18} \mathrm{H}_{19} \mathrm{ClN}_{2} \mathrm{O}_{4} \\
362.81\end{array}$} & $\mathrm{C}$ & 59.59 & 59.34 \\
\hline & & & & & $\mathrm{H}$ & 5.28 & 5.53 \\
\hline & & & & & $\mathrm{N}$ & 7.72 & 7.63 \\
\hline \multirow{3}{*}{$\mathrm{III}_{4}$} & \multirow{3}{*}{ 2,6-dichloro } & \multirow{3}{*}{$159-61$} & \multirow{3}{*}{67} & \multirow{3}{*}{$\begin{array}{c}\mathrm{C}_{18} \mathrm{H}_{18} \mathrm{Cl}_{2} \mathrm{~N}_{2} \mathrm{O}_{4} \\
397.25\end{array}$} & $\mathrm{C}$ & 54.42 & 54.10 \\
\hline & & & & & $\mathrm{H}$ & 4.53 & 4.70 \\
\hline & & & & & $\mathrm{N}$ & 7.05 & 6.95 \\
\hline \multirow{3}{*}{$\mathrm{III}_{5}$} & \multirow{3}{*}{$4-(\mathrm{Br})$} & \multirow{3}{*}{$248-50$} & \multirow{3}{*}{70} & \multirow{3}{*}{$\begin{array}{c}\mathrm{C}_{18} \mathrm{H}_{19} \mathrm{BrN}_{2} \mathrm{O}_{4} \\
407.26\end{array}$} & $\mathrm{C}$ & 53.08 & 52.70 \\
\hline & & & & & $\mathrm{H}$ & 4.70 & 4.90 \\
\hline & & & & & $\mathrm{N}$ & 6.88 & 6.82 \\
\hline \multirow{3}{*}{ III $_{6}$} & \multirow{3}{*}{$2-\left(\mathrm{CO}_{2} \mathrm{CH}_{3}\right)$} & \multirow{3}{*}{$150-1$} & & & $\mathrm{C}$ & 62.17 & 61.80 \\
\hline & & & 65 & $\begin{array}{c}\mathrm{C}_{20} \mathrm{H}_{22} \mathrm{~N}_{2} \mathrm{U}_{6} \\
38640\end{array}$ & $\mathrm{H}$ & 5.74 & 5.40 \\
\hline & & & & & $\mathrm{N}$ & 7.25 & 7.13 \\
\hline & & & & & $\mathrm{C}$ & 62.17 & 62.28 \\
\hline III $_{7}$ & $4-\left(\mathrm{CO}_{2} \mathrm{CH}_{3}\right)$ & $190-2$ & 71 & $\begin{array}{c}\mathrm{C}_{20} \mathrm{H}_{22} \mathrm{~N}_{2} \mathrm{U}_{6} \\
38640\end{array}$ & $\mathrm{H}$ & 5.74 & 6.00 \\
\hline & & & & & $\mathrm{N}$ & 7.25 & 7.15 \\
\hline
\end{tabular}


Table 2: 3-Cyano-4,6-dimethyl-2-substituted pyridines $\mathbf{V I}_{\mathbf{1 - 9}}$.

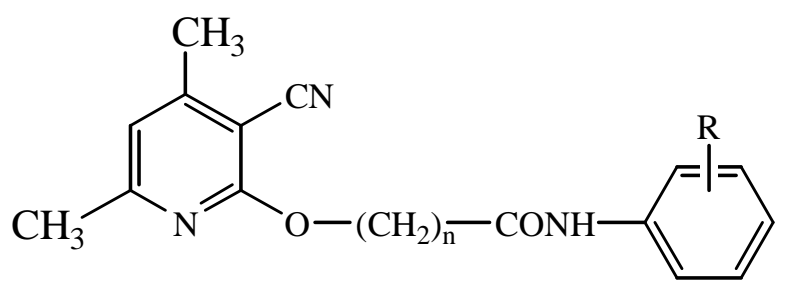

\begin{tabular}{|c|c|c|c|c|c|c|c|c|}
\hline \multirow{2}{*}{$\begin{array}{l}\text { Comp. } \\
\text { No. }\end{array}$} & \multirow{2}{*}{$\mathrm{R}$} & \multirow{2}{*}{$\mathrm{n}$} & \multirow{2}{*}{ M.P, ${ }^{\circ}$} & \multirow{2}{*}{$\begin{array}{c}\text { Yield } \\
\%\end{array}$} & \multirow{2}{*}{$\begin{array}{c}\text { Molecular formula } \\
\text { M.Wt }\end{array}$} & \multicolumn{3}{|c|}{ Elemental analyses } \\
\hline & & & & & & $\%$ & Calcd. & Found \\
\hline $\mathbf{V I}_{1}$ & $\mathrm{H}$ & 1 & $229-30$ & 80 & $\begin{array}{c}\mathrm{C}_{16} \mathrm{H}_{15} \mathrm{~N}_{3} \mathrm{O}_{2} \\
281.31\end{array}$ & $\begin{array}{l}\mathrm{C} \\
\mathrm{H} \\
\mathrm{N} \\
\end{array}$ & $\begin{array}{c}68.31 \\
5.37 \\
14.94 \\
\end{array}$ & $\begin{array}{c}68.28 \\
5.36 \\
14.88 \\
\end{array}$ \\
\hline $\mathbf{V I}_{2}$ & $4-\mathrm{CH}_{3}$ & 1 & $214-15$ & 82 & $\begin{array}{c}\mathrm{C}_{17} \mathrm{H}_{17} \mathrm{~N}_{3} \mathrm{O}_{2} \\
295.34\end{array}$ & $\begin{array}{l}\mathrm{C} \\
\mathrm{H} \\
\mathrm{N}\end{array}$ & $\begin{array}{c}69.14 \\
5.80 \\
14.23\end{array}$ & $\begin{array}{c}69.10 \\
5.72 \\
14.21\end{array}$ \\
\hline $\mathbf{V I}_{3}$ & $4-\mathrm{OCH}_{3}$ & 1 & 219.20 & 81 & $\begin{array}{c}\mathrm{C}_{17} \mathrm{H}_{17} \mathrm{~N}_{3} \mathrm{O}_{3} \\
311.34\end{array}$ & $\begin{array}{l}\mathrm{C} \\
\mathrm{H} \\
\mathrm{N} \\
\end{array}$ & $\begin{array}{c}65.58 \\
5.50 \\
13.50 \\
\end{array}$ & $\begin{array}{c}65.60 \\
5.63 \\
13.40 \\
\end{array}$ \\
\hline $\mathbf{V I}_{4}$ & $4-(\mathrm{Cl})$ & 1 & $170-1$ & 75 & $\begin{array}{c}\mathrm{C}_{16} \mathrm{H}_{14} \mathrm{ClN}_{3} \mathrm{O}_{2} \\
315.75\end{array}$ & $\begin{array}{l}\mathrm{C} \\
\mathrm{H} \\
\mathrm{N} \\
\end{array}$ & $\begin{array}{c}60.86 \\
4.47 \\
13.31 \\
\end{array}$ & $\begin{array}{c}60.98 \\
4.53 \\
13.25 \\
\end{array}$ \\
\hline $\mathrm{VI}_{5}$ & 2,6-dichloro & 1 & $319-20$ & 76 & $\begin{array}{c}\mathrm{C}_{16} \mathrm{H}_{13} \mathrm{Cl}_{2} \mathrm{~N}_{3} \mathrm{O}_{2} \\
350.20\end{array}$ & $\begin{array}{l}\mathrm{C} \\
\mathrm{H} \\
\mathrm{N} \\
\end{array}$ & $\begin{array}{c}54.87 \\
3.74 \\
12.00 \\
\end{array}$ & $\begin{array}{c}54.92 \\
3.75 \\
11.88 \\
\end{array}$ \\
\hline $\mathrm{VI}_{6}$ & $4-(\mathrm{Br})$ & 1 & $235-7$ & 72 & $\begin{array}{c}\mathrm{C}_{16} \mathrm{H}_{14} \mathrm{BrN}_{3} \mathrm{O}_{2} \\
360.20\end{array}$ & $\begin{array}{l}\mathrm{C} \\
\mathrm{H} \\
\mathrm{N} \\
\end{array}$ & $\begin{array}{c}53.35 \\
3.92 \\
11.67 \\
\end{array}$ & $\begin{array}{c}53.13 \\
3.95 \\
11.56 \\
\end{array}$ \\
\hline $\mathbf{V I}_{7}$ & $2-\mathrm{CO}_{2} \mathrm{CH}_{3}$ & 1 & $190-1$ & 79 & $\begin{array}{c}\mathrm{C}_{18} \mathrm{H}_{17} \mathrm{~N}_{3} \mathrm{O}_{4} \\
339.35\end{array}$ & $\begin{array}{l}\mathrm{C} \\
\mathrm{H} \\
\mathrm{N} \\
\end{array}$ & $\begin{array}{c}63.71 \\
5.05 \\
12.38 \\
\end{array}$ & $\begin{array}{c}63.62 \\
5.03 \\
12.30 \\
\end{array}$ \\
\hline $\mathbf{V I}_{8}$ & 2,6-dichloro & 2 & $269-71$ & 65 & $\begin{array}{c}\mathrm{C}_{17} \mathrm{H}_{15} \mathrm{Cl}_{2} \mathrm{~N}_{3} \mathrm{O}_{2} \\
364.23\end{array}$ & $\begin{array}{l}\mathrm{C} \\
\mathrm{H} \\
\mathrm{N} \\
\end{array}$ & $\begin{array}{c}56.06 \\
4.15 \\
11.54 \\
\end{array}$ & $\begin{array}{c}56.12 \\
4.32 \\
11.75 \\
\end{array}$ \\
\hline $\mathbf{V I}_{9}$ & $4-(\mathrm{Br})$ & 2 & $200-2$ & 62 & $\begin{array}{c}\mathrm{C}_{17} \mathrm{H}_{16} \mathrm{BrN}_{3} \mathrm{O}_{2} \\
374.23\end{array}$ & $\begin{array}{l}\mathrm{C} \\
\mathrm{H} \\
\mathrm{N} \\
\end{array}$ & $\begin{array}{c}54.56 \\
4.31 \\
11.23 \\
\end{array}$ & $\begin{array}{c}54.49 \\
4.20 \\
11.31 \\
\end{array}$ \\
\hline
\end{tabular}


Table 3: 3-Cyano-4,6-dimethyl -2-(substitutedthio) pyridines $\mathbf{X}_{\mathbf{1 - 1 2}}$.<smiles>[R]c1cccc(NC(=O)CCSc2nc(C)cc(C)c2C#N)c1</smiles>

\begin{tabular}{|c|c|c|c|c|c|c|c|c|}
\hline \multirow{2}{*}{$\begin{array}{l}\text { Comp. } \\
\text { No. }\end{array}$} & \multirow{2}{*}{$\mathrm{R}$} & \multirow{2}{*}{$\mathrm{n}$} & \multirow{2}{*}{ M.P, } & \multirow{2}{*}{$\begin{array}{l}\text { Yield } \\
\%\end{array}$} & \multirow{2}{*}{$\begin{array}{c}\text { Molecular formula } \\
\text { M.Wt }\end{array}$} & \multicolumn{3}{|c|}{ Elemental analyses } \\
\hline & & & & & & $\%$ & Calcd. & Found \\
\hline $\mathbf{X}_{1}$ & $\mathrm{H}$ & 1 & $220-2$ & 75 & $\begin{array}{c}\mathrm{C}_{16} \mathrm{H}_{15} \mathrm{~N}_{3} \mathrm{O}_{2} \\
297.38\end{array}$ & $\begin{array}{l}\mathrm{C} \\
\mathrm{H} \\
\mathrm{N}\end{array}$ & $\begin{array}{c}64.62 \\
5.08 \\
14.13\end{array}$ & $\begin{array}{c}64.35 \\
5.15 \\
14.20\end{array}$ \\
\hline $\mathbf{X}_{2}$ & $4-\mathrm{CH}_{3}$ & 1 & $210-11$ & 80 & $\begin{array}{c}\mathrm{C}_{17} \mathrm{H}_{17} \mathrm{~N}_{3} \mathrm{OS} \\
311.40\end{array}$ & $\begin{array}{l}\mathrm{C} \\
\mathrm{H} \\
\mathrm{N}\end{array}$ & $\begin{array}{c}65.57 \\
5.50 \\
13.49\end{array}$ & $\begin{array}{c}65.70 \\
5.59 \\
13.40\end{array}$ \\
\hline $\mathbf{X}_{3}$ & $4-\mathrm{OCH}_{3}$ & 1 & $265-6$ & 77 & $\begin{array}{c}\mathrm{C}_{17} \mathrm{H}_{17} \mathrm{~N}_{3} \mathrm{O}_{2} \mathrm{~S} \\
327.48\end{array}$ & $\begin{array}{l}\mathrm{C} \\
\mathrm{H} \\
\mathrm{N} \\
\end{array}$ & $\begin{array}{c}62.36 \\
5.23 \\
12.83 \\
\end{array}$ & $\begin{array}{c}62.01 \\
5.20 \\
12.66 \\
\end{array}$ \\
\hline $\mathbf{X}_{4}$ & 4-(Br) & 1 & $229-31$ & 80 & $\begin{array}{c}\mathrm{C}_{16} \mathrm{H}_{14} \mathrm{Br} \mathrm{N}_{3} \mathrm{OS} \\
376.27\end{array}$ & $\begin{array}{l}\mathrm{C} \\
\mathrm{H} \\
\mathrm{N} \\
\end{array}$ & $\begin{array}{c}51.07 \\
3.75 \\
11.17 \\
\end{array}$ & $\begin{array}{c}50.85 \\
3.84 \\
11.18 \\
\end{array}$ \\
\hline $\mathbf{X}_{5}$ & $4-(\mathrm{Cl})$ & 1 & $214-5$ & 71 & $\begin{array}{c}\mathrm{C}_{16} \mathrm{H}_{14} \mathrm{ClN}_{3} \mathrm{OS} \\
331.82\end{array}$ & $\begin{array}{l}\mathrm{C} \\
\mathrm{H} \\
\mathrm{N} \\
\end{array}$ & $\begin{array}{c}57.91 \\
4.25 \\
12.66 \\
\end{array}$ & $\begin{array}{c}57.73 \\
4.22 \\
12.55 \\
\end{array}$ \\
\hline $\mathbf{X}_{6}$ & 2,6-dichloro & 1 & $214-6$ & 81 & $\begin{array}{c}\mathrm{C}_{16} \mathrm{H}_{13} \mathrm{Cl}_{2} \mathrm{~N}_{3} \mathrm{OS} \\
366.27\end{array}$ & $\begin{array}{l}\mathrm{C} \\
\mathrm{H} \\
\mathrm{N} \\
\end{array}$ & $\begin{array}{c}52.47 \\
3.58 \\
11.47 \\
\end{array}$ & $\begin{array}{c}52.49 \\
3.56 \\
11.45 \\
\end{array}$ \\
\hline $\mathbf{X}_{7}$ & $2-\mathrm{CO}_{2} \mathrm{CH}_{3}$ & 1 & $235-6$ & 70 & $\begin{array}{c}\mathrm{C}_{18} \mathrm{H}_{17} \mathrm{~N}_{3} \mathrm{O}_{3} \mathrm{~S} \\
355.41\end{array}$ & $\begin{array}{l}\mathrm{C} \\
\mathrm{H} \\
\mathrm{N}\end{array}$ & $\begin{array}{c}60.83 \\
4.82 \\
11.82\end{array}$ & $\begin{array}{c}60.70 \\
4.60 \\
11.75\end{array}$ \\
\hline $\mathbf{X}_{8}$ & $4-\mathrm{CO}_{2} \mathrm{CH}_{3}$ & 1 & $214-5$ & 67 & $\begin{array}{c}\mathrm{C}_{18} \mathrm{H}_{17} \mathrm{~N}_{3} \mathrm{O}_{3} \mathrm{~S} \\
355.41\end{array}$ & $\begin{array}{l}\mathrm{C} \\
\mathrm{H} \\
\mathrm{N} \\
\end{array}$ & $\begin{array}{c}60.83 \\
4.82 \\
11.82 \\
\end{array}$ & $\begin{array}{c}61.05 \\
4.90 \\
11.75 \\
\end{array}$ \\
\hline $\mathbf{X}_{9}$ & $\mathrm{H}$ & 2 & $140-1$ & 65 & $\begin{array}{c}\mathrm{C}_{17} \mathrm{H}_{17} \mathrm{~N}_{3} \mathrm{OS} \\
311.40\end{array}$ & $\begin{array}{l}\mathrm{C} \\
\mathrm{H} \\
\mathrm{N}\end{array}$ & $\begin{array}{c}65.57 \\
5.50 \\
13.49\end{array}$ & $\begin{array}{c}65.46 \\
5.41 \\
13.52\end{array}$ \\
\hline $\mathbf{X}_{10}$ & $\mathrm{CH}_{3}$ & 2 & $120-1$ & 61 & $\begin{array}{c}\mathrm{C}_{18} \mathrm{H}_{19} \mathrm{~N}_{3} \mathrm{OS} \\
325.43\end{array}$ & $\begin{array}{l}\mathrm{C} \\
\mathrm{H} \\
\mathrm{N} \\
\end{array}$ & $\begin{array}{c}66.43 \\
5.88 \\
12.91 \\
\end{array}$ & $\begin{array}{c}66.45 \\
5.72 \\
12.88 \\
\end{array}$ \\
\hline$X_{11}$ & $4-(\mathrm{Br})$ & 2 & $140-1$ & 62 & $\begin{array}{c}\mathrm{C}_{17} \mathrm{H}_{16} \mathrm{BrN}_{3} \mathrm{OS} \\
390.30\end{array}$ & $\begin{array}{l}\mathrm{C} \\
\mathrm{H} \\
\mathrm{N} \\
\end{array}$ & $\begin{array}{c}52.31 \\
4.13 \\
10.77 \\
\end{array}$ & $\begin{array}{c}52.48 \\
4.11 \\
10.89 \\
\end{array}$ \\
\hline $\mathbf{X}_{12}$ & 2,6-dichloro & 2 & $157-8$ & 65 & $\begin{array}{c}\mathrm{C}_{17} \mathrm{H}_{15} \mathrm{Cl}_{2} \mathrm{~N}_{3} \mathrm{OS} \\
380.20\end{array}$ & $\begin{array}{l}\mathrm{C} \\
\mathrm{H} \\
\mathrm{N} \\
\end{array}$ & $\begin{array}{c}53.69 \\
3.98 \\
11.05\end{array}$ & $\begin{array}{c}53.61 \\
4.01 \\
10.95\end{array}$ \\
\hline
\end{tabular}


Table 4: Spectral data of some new compounds (III-X).

\begin{tabular}{|c|c|c|}
\hline $\begin{array}{c}\text { Comp. } \\
\text { No. }\end{array}$ & & Spectral data IR $\left(\mathrm{cm}^{-1}\right),{ }^{1} \mathrm{HNMR}(\delta \mathrm{ppm}$.$) , Mass (\mathrm{m} / \mathrm{z}, \%)$ \\
\hline III $_{1}$ & $\begin{array}{c}\mathrm{IR} \\
{ }^{1} \mathrm{HNMR} \\
\left(\mathrm{CDCl}_{3}\right)\end{array}$ & $\begin{array}{l}1639(\mathrm{CONH}), 1735\left(\mathrm{COOC}_{2} \mathrm{H}_{5}\right), 3276(\mathrm{CONHPh}) \\
1.30\left(\mathrm{t}, 3 \mathrm{H}, \mathrm{CH}_{3}-\mathrm{CH}_{2}-\mathrm{O}-\right), 2.20\left(\mathrm{~S}, 3 \mathrm{H}, \mathrm{CH}_{3} \text { at } 6-\text { position }\right), 2.45\left(\mathrm{~s}, 3 \mathrm{H}, \mathrm{CH}_{3} \text { at }\right. \\
\text { 4-position }), 4.35\left(\mathrm{q}, 2 \mathrm{H}, \mathrm{CH}_{3}-\mathrm{CH}_{2}-\mathrm{O}-\right), 4.90\left(\mathrm{~s}, 2 \mathrm{H},-\mathrm{o}-\mathrm{CH}_{2} \mathrm{CO}\right), 6.05(\mathrm{~s}, 1 \mathrm{H} \text {, } \\
\mathrm{CH} \text { at } \mathrm{C}_{5} \text {-of pyridine), 7.00-7.50 (m, 5H, aromatic protons), } 9.70(\mathrm{~s}, 1 \mathrm{H}, \mathrm{NH}) \text {. }\end{array}$ \\
\hline $\mathrm{III}_{3}$ & $\begin{array}{l}{ }^{1} \mathrm{HNMR} \\
\left(\mathrm{CDCl}_{3}\right)\end{array}$ & $\begin{array}{l}1.35\left(\mathrm{t}, 3 \mathrm{H}, \mathrm{CH}_{3}\right), 2.24\left(\mathrm{~s}, 3 \mathrm{H}, \mathrm{CH}_{3} \text { at-6-position }\right), 2.51\left(\mathrm{~s}, 3 \mathrm{H}, \mathrm{CH}_{3} \text { at } 4-\right. \\
\text { position }), 4.83\left(\mathrm{q}, 2 \mathrm{H}, \mathrm{CH}_{3}-\mathrm{CH}_{2}-\mathrm{O}-\right), 4.83\left(\mathrm{~s}, 2 \mathrm{H}, \mathrm{OCH}_{2} \mathrm{CO}\right), 6.08(\mathrm{~s}, \\
\left.1 \mathrm{H}, \mathrm{CH} \text { at } \mathrm{C}_{5} \text {-of pyridine }\right), 7.17\left(\mathrm{~d}, 2 \mathrm{H}, \text { aromatic protons at } \mathrm{C}_{1} \text { and } \mathrm{C}_{6}\right), 7.38 \\
\left(\mathrm{~d}, 2 \mathrm{H} \text {, aromatic protons at } \mathrm{C}_{3} \text { and } \mathrm{C}_{5}\right), 9.62(\mathrm{~s}, 1 \mathrm{H}, \mathrm{NH}) \text {. }\end{array}$ \\
\hline $\mathrm{III}_{4}$ & $\begin{array}{c}\text { IR } \\
{ }^{1} \mathrm{HNMR} \\
\left(\text { acetone- } \mathrm{d}_{6}\right)\end{array}$ & $\begin{array}{l}1643(\mathrm{CONH}), 1719\left(\mathrm{COOC}_{2} \mathrm{H}_{5}\right), 3194(\mathrm{CONHPh}) \\
1.26\left(\mathrm{t}, 3 \mathrm{H}, \mathrm{CH}_{3}-\mathrm{CH}_{2}-\mathrm{O}-\right), 2.11\left(\mathrm{~s}, 3 \mathrm{H}, \mathrm{CH}_{3} \text { at 6-position }\right), 2.44\left(\mathrm{~s}, 3 \mathrm{H}, \mathrm{CH}_{3} \text { at }\right. \\
\text { 4-position }), 2.24\left(\mathrm{q}, 2 \mathrm{H}, \mathrm{CH}_{3}-\mathrm{CH}_{2}-\mathrm{O}-\right), 5.01\left(\mathrm{~s}, 2 \mathrm{H}, \mathrm{OCH}_{2} \mathrm{CO}\right), 6.07(\mathrm{~s}, 1 \mathrm{H} \text {, } \\
\mathrm{CH} \text { at } \mathrm{C}_{5} \text {-of pyridine), 7.33-7.48(m,3H, aromatic protons), } 9.38(\mathrm{~s}, 1 \mathrm{H}, \mathrm{NH}) \text {. }\end{array}$ \\
\hline III $_{7}$ & $\begin{array}{c}\mathrm{IR} \\
{ }^{1} \mathrm{HNMR} \\
\left(\mathrm{CDCl}_{3}\right)\end{array}$ & $\begin{array}{l}1739,1725\left(\mathrm{COOC}_{2} \mathrm{H}_{5}, \mathrm{p}-\mathrm{COOC}_{2} \mathrm{H}_{5}\right), 1637(\mathrm{CONH}), 3280(\mathrm{CONHPh}), \\
1.31\left(\mathrm{t}, 3 \mathrm{H}, \mathrm{CH}_{3}-\mathrm{CH}_{2}-\mathrm{O}-\right), 2.25\left(\mathrm{~s}, 3 \mathrm{H}, \mathrm{CH}_{3} \text { at } 6-\text { position}\right), 2.48\left(\mathrm{~s}, 3 \mathrm{H}, \mathrm{CH}_{3}\right. \\
\text { at 4-position), } 3.86\left(\mathrm{~s}, 3 \mathrm{H}, \mathrm{p}-\mathrm{OCH}_{3}\right), 3.35\left(\mathrm{q}, 2 \mathrm{H},-\mathrm{CH}_{3}-\mathrm{CH}_{2}-\mathrm{O}-\right), 4.91(\mathrm{~s}, \\
\left.2 \mathrm{H},-\mathrm{OCH} \mathrm{CH}_{2}-\mathrm{CO}\right), 6.10\left(\mathrm{~s}, 1 \mathrm{H}, \mathrm{CH} \text { at } \mathrm{C}_{5} \text {-of pyridine }\right), 7.44(\mathrm{~d}, 2 \mathrm{H}, \text { aromatic } \\
\left.\text { protons at } \mathrm{C}_{2} \text { and } \mathrm{C}_{6}\right), 7.80\left(\mathrm{~d}, 2 \mathrm{H}, \text { aromatic protons at } \mathrm{C}_{3} \text { and } \mathrm{C}_{5}\right), 10.03 \\
(\mathrm{~s}, 1 \mathrm{H}, \mathrm{NH}) \text {. }\end{array}$ \\
\hline $\mathbf{V I}_{1}$ & $\begin{array}{c}{ }^{1} \mathrm{HNMR} \\
\left(\mathrm{DMSO}^{-} \mathrm{d}_{6}\right)\end{array}$ & $\begin{array}{l}2.36\left(\mathrm{~s}, 3 \mathrm{H}, \mathrm{CH}_{3} \text { at } 6 \text { position }\right), 2.40\left(\mathrm{~s}, 3 \mathrm{H}, \mathrm{CH}_{3} \text { at } 4 \text { position }\right), 4.89(\mathrm{~s}, 2 \mathrm{H} \text {, } \\
\left.\mathrm{OCH}_{2} \mathrm{CO}\right), 6.38\left(\mathrm{~s}, 1 \mathrm{H}, \mathrm{CH} \text { at } \mathrm{C}_{5} \text {-of pyridine }\right), 7.10(\mathrm{t}, 1 \mathrm{H} \text {, aromatic proton } \\
\text { at } \mathrm{C} 4 \text {-of phenyl ring), } 7.35\left(\mathrm{t}, 2 \mathrm{H} \text {, aromatic protons at } \mathrm{C}_{2}, 5 \text {-of phenyl ring), }\right. \\
7.60\left(\mathrm{~d}, 2 \mathrm{H} \text {, aromatic protons at } \mathrm{C}_{1,6}\right), 10.44(\mathrm{~s}, 1 \mathrm{H}, \mathrm{NH}) .\end{array}$ \\
\hline $\mathbf{V I}_{2}$ & 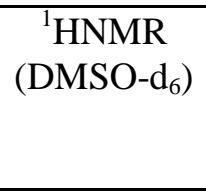 & $\begin{array}{l}2.26\left(\mathrm{~s}, 3 \mathrm{H}, \mathrm{CH}_{3} \text { at the p-position }\right), 2.40\left(\mathrm{~d}, 6 \mathrm{H}, 2 \mathrm{CH}_{3} \text {, at } 6 \text { and } 4 \text {-positions }\right) \text {, } \\
4.87\left(\mathrm{~s}, 2 \mathrm{H},-\mathrm{OCH}_{2} \mathrm{CO}\right), 6.38\left(\mathrm{~s}, 1 \mathrm{H}, \mathrm{CH} \text { at } \mathrm{C}_{5} \text {-of pyridine }\right), 7.15(\mathrm{~d}, 2 \mathrm{H} \text { at } \\
\mathrm{C}_{3,5^{-}} \text {of the aromatic ring), } 7.45\left(\mathrm{~d}, 2 \mathrm{H} \text { at } \mathrm{C}_{2,6^{-}} \text {of the aromatic ring), } 10.26(\mathrm{~s} \text {, }\right. \\
1 \mathrm{H}, \mathrm{NH}) \text {. }\end{array}$ \\
\hline $\mathbf{V I}_{3}$ & 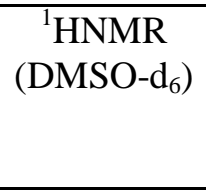 & $\begin{array}{l}2.35\left(\mathrm{~s}, 3 \mathrm{H}, \mathrm{CH}_{3} \text { at } 6 \text { position }\right), 2.39\left(\mathrm{~s}, 3 \mathrm{H}, \mathrm{CH}_{3} \text { at } 4 \text {-position }\right), 3.73(\mathrm{~s}, 3 \mathrm{H} \text {, } \\
\mathrm{OCH}_{3} \text { at p-position), } 4.86\left(\mathrm{~s}, 2 \mathrm{H}, \mathrm{OCH}_{2} \mathrm{CO}\right), 6.37\left(\mathrm{~s}, 1 \mathrm{H}, \mathrm{CH} \text { at } \mathrm{C}_{5} \text {-of }\right. \\
\text { pyridine }), 6.90\left(\mathrm{~d}, 2 \mathrm{H}, \text { at } \mathrm{C}_{2,6} \text {-aromatic protons }\right), 7.50\left(\mathrm{~d}, 2 \mathrm{H} \text {, at } \mathrm{C}_{3,5^{-}}\right. \\
\text {aromatic position), } 10.31(\mathrm{~s}, 1 \mathrm{H}, \mathrm{NH}) \text {. }\end{array}$ \\
\hline $\mathbf{V I}_{4}$ & $\begin{array}{c}{ }^{1} \mathrm{HNMR} \\
\left(\mathrm{CDCl}_{3}\right) \\
\mathrm{Ms}\end{array}$ & $\begin{array}{l}2.43\left(\mathrm{~d}, 6 \mathrm{H}, 2 \mathrm{CH}_{3} \text { at } 6,4-\text { positions }\right), 4.94\left(\mathrm{~s}, 2 \mathrm{H}, \mathrm{OCH}_{2} \mathrm{CO}\right), 6.17(\mathrm{~s}, 1 \mathrm{H} \text {, } \\
\left.\mathrm{CH} \text { at } \mathrm{C}_{5} \text {-of pyridine }\right), 7.12-7.60\left(\mathrm{~m}, 5 \mathrm{H} \text {, aromatic protons and } \mathrm{CDCl}_{3}\right. \\
\text { proton }), 9.63(\mathrm{~s}, 1 \mathrm{H}, \mathrm{NH}) . \\
315,317\left(\mathrm{M}^{+}, \mathrm{M}+4,3.00,1.21 \%\right), 189(\mathrm{~m} / \mathrm{e} \text { base } 100 \%) \text {. }\end{array}$ \\
\hline $\mathbf{V I}_{5}$ & IR & $1671(\mathrm{CONHPh}), 2217(\mathrm{CN}), 3195(\mathrm{CONHPh})$. \\
\hline $\mathbf{V I}_{6}$ & $\begin{array}{l}{ }^{1} \text { HNMR } \\
\text { (acetone } \mathrm{d}_{6} \text { ) }\end{array}$ & $\begin{array}{l}2.37\left(\mathrm{~s}, 3 \mathrm{H}, \mathrm{CH}_{3} \text { at 6-position }\right), 2.48\left(\mathrm{~s}, 3 \mathrm{H}, \mathrm{CH}_{3} \text { at } 4 \text {-position }\right), 4.97(\mathrm{~s}, 2 \mathrm{H} \text {, } \\
\left.\mathrm{OCH}_{2} \mathrm{CO}\right), 6.30\left(\mathrm{~s}, 1 \mathrm{H}, \mathrm{CH} \text { at } \mathrm{C}_{5^{-}} \text {of pyridine }\right), 7.47\left(\mathrm{~d}, 2 \mathrm{H} \text {, aromatic at } \mathrm{C}_{2}\right. \\
\left.\text { and } \mathrm{C}_{6}\right), 7.60\left(\mathrm{~d}, 2 \mathrm{H}, \text { aromatic } \mathrm{C}_{3}, \mathrm{C}_{5}\right), 9.65(\mathrm{~s}, 1 \mathrm{H}, \mathrm{NH})\end{array}$ \\
\hline $\mathbf{V I}_{7}$ & $\begin{array}{c}\mathrm{IR} \\
{ }^{1} \mathrm{HNMR} \\
\left(\mathrm{CDCl}_{3}\right)\end{array}$ & 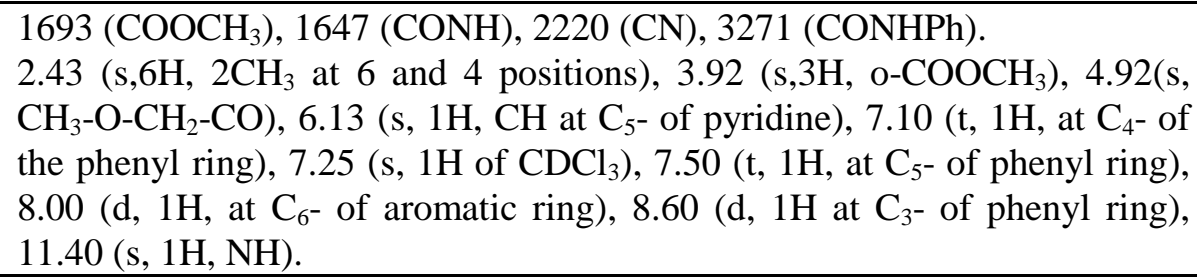 \\
\hline $\mathbf{V I}_{8}$ & $\begin{array}{c}\text { IR } \\
{ }^{1} \mathrm{HNMR} \\
\left(\text { acetone } \mathrm{d}_{6}\right)\end{array}$ & $\begin{array}{l}1661(\mathrm{CONH}), 2216(\mathrm{CN}), 3242(\mathrm{CONHPh}) \text {. } \\
2.35\left(\mathrm{~s}, 3 \mathrm{H}, \mathrm{CH}_{3} \text { at } 6 \text {-position }\right), 2.80\left(\mathrm{~s}, 3 \mathrm{H}, \mathrm{CH}_{3} \text { at 4-position }\right), 2.95(\mathrm{t}, 2 \mathrm{H}, \\
\left.-\mathrm{CH}_{2} \mathrm{CO}\right), 3.95\left(\mathrm{t}, 2 \mathrm{H}, \mathrm{OCH}_{2}-\mathrm{CH}_{2}\right), 6.12\left(\mathrm{~s}, 1 \mathrm{H}, \mathrm{CH} \text { at } \mathrm{C}_{5} \text {-of pyridine), }\right. \\
7.31-7.49(\mathrm{~m}, 3 \mathrm{H} \text {, aromatic }), 9.08(\mathrm{~s}, 1 \mathrm{H}, \mathrm{NH}) .\end{array}$ \\
\hline
\end{tabular}


Table 4: continued

\begin{tabular}{|c|c|c|}
\hline $\begin{array}{c}\text { Comp. } \\
\text { No. }\end{array}$ & & Spectral data IR $\left(\mathrm{cm}^{-1}\right),{ }^{1} \mathrm{HNMR}(\delta \mathrm{ppm}$.$) , Mass (\mathrm{m} / \mathrm{z}, \%)$ \\
\hline $\mathbf{V I}_{9}$ & $\begin{array}{l}{ }^{1} \mathrm{HNMR} \\
\left(\mathrm{CDCl}_{3}\right)\end{array}$ & $\begin{array}{l}\text { 2.30 (s, 3H, } \mathrm{CH} \text { at 6-position), } 2.51\left(\mathrm{~s}, 3 \mathrm{H}, \mathrm{CH}_{3} \text { at 4-position), } 2.81(\mathrm{t}, 2 \mathrm{H},\right. \\
\left.\mathrm{CH}_{2} \mathrm{CO}\right), 4.27\left(\mathrm{t}, 2 \mathrm{H}, \mathrm{OCH}_{2}\right), 6.00\left(\mathrm{~s}, 1 \mathrm{H}, \mathrm{CH} \text { at } \mathrm{C}_{5} \text {-of pyridine), 7.10-7.80 }\right. \\
(\mathrm{m}, 4 \text {-aromatic protons }), 9.82(\mathrm{~s}, 1 \mathrm{H}, \mathrm{NH}) .\end{array}$ \\
\hline VIII & $\begin{array}{l}\text { IR } \\
{ }^{1} \mathrm{HNMR} \\
\left(\mathrm{DMSO}-\mathrm{d}_{6}\right) \\
\mathrm{Ms} \\
\end{array}$ & $\begin{array}{l}2216(\mathrm{CN}), 3356(\mathrm{SH}) \\
2.35\left(\mathrm{~s}, 6 \mathrm{H}, 2 \mathrm{CH}_{3} \text { at } 6.4 \text { position }\right), 6.69\left(\mathrm{~s}, 1 \mathrm{H}, \mathrm{CH} \text { at } \mathrm{C}_{5} \text {-of pyridine }\right), 13.80 \\
(\mathrm{~s}, 1 \mathrm{H}, \mathrm{SH}) . \\
\left.\mathrm{m} / \mathrm{z} 164\left(\mathrm{M}^{+}, 9.21 \%\right), \mathrm{M} / \mathrm{z} 55 \text { (base } 100 \%\right) .\end{array}$ \\
\hline $\mathbf{X}_{1}$ & $\begin{array}{c}{ }^{1} \mathrm{HNMR} \\
\left(\mathrm{DMSO}-\mathrm{d}_{6}\right)\end{array}$ & $\begin{array}{l}2.52\left(\mathrm{~s}, 3 \mathrm{H}, \mathrm{CH}_{3} \text { at } 6-\text { position), } 2.81\left(\mathrm{~s}, 3 \mathrm{H}, \mathrm{CH}_{3} \text { at } 4-\text { position }\right), 6.91(\mathrm{~s}, 2 \mathrm{H} \text {, }\right. \\
\left.\mathrm{s}-\mathrm{CH}_{2} \mathrm{CO}\right), 6.98(\mathrm{~s}, 1 \mathrm{H},-\mathrm{H} \text { of pyridine }), 7.07-7.75(\mathrm{~m}, 7 \mathrm{H} \text {, aromatic protons } \\
\text { and }-\mathrm{SCH}_{2} \text {-protons), } 9.42(\mathrm{~s}, 1 \mathrm{H}, \mathrm{NH}) .\end{array}$ \\
\hline $\mathbf{X}_{2}$ & $\begin{array}{c}{ }^{1} \mathrm{HNMR} \\
\left(\text { DMSO-d }_{6}\right)\end{array}$ & $\begin{array}{l}2.28\left(\mathrm{~s}, 3 \mathrm{H}, \mathrm{CH}_{3} \text { at p-position of aromatic ring }\right), 2.52\left(\mathrm{~s}, 3 \mathrm{H}, \mathrm{CH}_{3} \text { at } 6-\right. \\
\text { position }), 2.75\left(\mathrm{~s}, 3 \mathrm{H}, \mathrm{CH}_{3} \text { at } 4 \text {-position }\right), 6.95\left(\mathrm{~s}, 2 \mathrm{H}, \mathrm{SCH}_{2} \mathrm{CO}\right), 7.05(\mathrm{~s}, \\
1 \mathrm{H} \text { at } 5 \text {-position }), 7.15\left(\mathrm{~d}, 2 \mathrm{H} \text { aromatic protons at } \mathrm{C}_{3}, 5\right), 7.58(\mathrm{~d}, 2 \mathrm{H}, \\
\left.\text { aromatic protons at } \mathrm{C}_{2,6}\right), 9.34(\mathrm{~s}, 1 \mathrm{H}, \mathrm{NH}) .\end{array}$ \\
\hline $\mathbf{X}_{4}$ & $\begin{array}{c}\text { IR } \\
{ }^{1} \mathrm{HNMR} \\
\left(\mathrm{DMSO}-\mathrm{d}_{6}\right)\end{array}$ & $\begin{array}{l}1643(\mathrm{CONH}), 3320(\mathrm{NH}), 3468\left(\mathrm{SCH}_{2}\right) \\
2.51\left(\mathrm{~s}, 3 \mathrm{H}, \mathrm{CH}_{3} \text { at } 6 \text {-position), } 2.74\left(\mathrm{~s}, 3 \mathrm{H}, \mathrm{CH}_{3} \text { at } 4 \text {-positions }\right), 3.42(\mathrm{~s}, 2 \mathrm{H} \text {, }\right. \\
\left.\mathrm{SCH}_{2} \mathrm{CO}\right), 7.03(\mathrm{~s}, 1 \mathrm{H}, \mathrm{CH} \text { of pyridine }), 7.51\left(\mathrm{~d}, 2 \mathrm{H} \text {, at } \mathrm{C}_{2,5^{-}} \text {of aromatic }\right) \text {, } \\
7.60\left(\mathrm{~d}, 2 \mathrm{H} \text {, at } \mathrm{C}_{3,5^{-}} \text {of aromatic }\right), 9.51(\mathrm{~s}, 1 \mathrm{H}, \mathrm{NH}) .\end{array}$ \\
\hline $\mathbf{X}_{4}$ & $\begin{array}{l}{ }^{1} \mathrm{HNMR} \\
\left(\mathrm{CDCl}_{3}\right)\end{array}$ & $\begin{array}{l}2.60\left(\mathrm{~s}, 3 \mathrm{H}, \mathrm{CH}_{3} \text { at } 6 \text {-position }\right), 2.76\left(\mathrm{~s}, 3 \mathrm{H}, \mathrm{CH}_{3} \text { at 4-positions }\right), 6.47(\mathrm{~s}, 2 \mathrm{H}, \\
\left.\mathrm{SCH}_{2} \mathrm{CO}\right), 6.90(\mathrm{~s}, 1 \mathrm{H}, \mathrm{CH} \text { of pyridine }), 7.14(\mathrm{~s}, 1 \mathrm{H}, \mathrm{NH}), 7.46-7.47(\mathrm{~m}, 4 \mathrm{H} \text {, } \\
\text { aromatic protons). }\end{array}$ \\
\hline $\mathbf{X}_{5}$ & $\begin{array}{c}{ }^{1} \text { HNMR } \\
\left.\text { (acetone } \mathrm{d}_{6}\right) \\
\text { Ms }\end{array}$ & $\begin{array}{l}2.51\left(\mathrm{~s}, 3 \mathrm{H}, \mathrm{CH}_{3} \text { at } 6-\text { position }\right), 2.81\left(\mathrm{~s}, 3 \mathrm{H}, \mathrm{CH}_{3} \text {, at } 4-\text { position }\right), 6.93(\mathrm{~s}, 2 \mathrm{H} \text {, } \\
\left.\mathrm{SCH}_{2} \mathrm{CO}\right), 7.03\left(\mathrm{~s}, 1 \mathrm{H}, \mathrm{CH} \text { of pyridine), } 7.32\left(\mathrm{~d}, 2 \mathrm{H} \text {, aromatic at } \mathrm{C}_{2} \text { and }\right.\right. \\
\left.\mathrm{C}_{6}\right), 7.78\left(\mathrm{~d}, 2 \mathrm{H} \text {, aromatic at } \mathrm{C}_{3} \text { and } \mathrm{C}_{5}\right), 8.74(\mathrm{~s}, 1 \mathrm{H}, \mathrm{NH}) \text {. } \\
331,335\left(\mathrm{M}, \mathrm{M}^{+} 4,3.00,0.72 \% \text { respectively), } 218 \text { (base } 100 \%\right) \text {. }\end{array}$ \\
\hline $\mathbf{X}_{7}$ & $\begin{array}{c}\text { IR } \\
{ }^{1} \mathrm{HNMR} \\
\left(\mathrm{DMSO}-\mathrm{d}_{6}\right)\end{array}$ & $\begin{array}{l}1699\left(\mathrm{COOCH}_{3}\right), 1594(\mathrm{CONH}), 3319(\mathrm{CONHPh}), 3482\left(\mathrm{SCH}_{2}\right), \\
2.51\left(\mathrm{~s}, 3 \mathrm{H}, \mathrm{CH}_{3} \text { at } 6 \text {-position }\right), 2.76\left(\mathrm{~s}, 3 \mathrm{H}, \mathrm{CH}_{3} \text { at } 4-\text { position }\right), 3.96(\mathrm{~s}, 3 \mathrm{H}, \\
\left.\mathrm{o}^{-} \mathrm{CO}_{2} \mathrm{CH}_{3} \text { of phenyl ring }\right), 7.01\left(\mathrm{~s}, 2 \mathrm{H}, \mathrm{SCH}_{2} \mathrm{CO}\right), 7.07(\mathrm{~s}, 1 \mathrm{H}, \mathrm{CH} \text { of } \\
\text { pyridine }), 7.22\left(\mathrm{t}, 1 \mathrm{H} \text { at } \mathrm{C}_{5^{-}} \text {-of aromatic ring), } 7.58(\mathrm{t}, 1 \mathrm{H} \text {, at } 4 \text {-aromatic }\right. \\
\text { position), } 8.04\left(\mathrm{~d}, 1 \mathrm{H}, \text { at } \mathrm{C}_{6^{-}} \text {of the aromatic ring), } 8.29\left(\mathrm{~d}, 1 \mathrm{H} \text { at } \mathrm{C}_{3^{-}}\right.\right. \\
\text {aromatic position), } 11.01(\mathrm{~s}, 1 \mathrm{H}, \mathrm{NH}) \text {. }\end{array}$ \\
\hline$\overline{\mathbf{X}_{8}}$ & $\begin{array}{l}{ }^{1} \mathrm{HNMR} \\
\left(\mathrm{CDCl}_{3}\right)\end{array}$ & $\begin{array}{l}2.61\left(\mathrm{~s}, 3 \mathrm{H}, \mathrm{CH}_{3} \text {, at 6-position), } 2.77(\mathrm{~s}, 3 \mathrm{H}, \mathrm{CH} 3 \text { at } 4 \text {-position }), 3.91(\mathrm{~s},\right. \\
\left.3 \mathrm{H}, \mathrm{p}-\mathrm{OCH}_{3}\right), 6.53\left(\mathrm{~s}, 2 \mathrm{H}, \mathrm{SCH} \mathrm{CO}_{2} \mathrm{CO}\right), 6.92(\mathrm{~s}, 1 \mathrm{H}, \mathrm{CH} \text { of pyridine }), 7.26(\mathrm{~s}, \\
\left.1 \mathrm{H}, \mathrm{CDCl}_{3}\right), 7.28(\mathrm{~s}, 1 \mathrm{H}, \mathrm{NH}), 7.69\left(\mathrm{~d}, 2 \mathrm{H} \text {, aromatic at } \mathrm{C}_{2} \text { and } \mathrm{C}_{6}\right), 8.05(\mathrm{~d}, \\
\left.2 \mathrm{H} \text {, aromatic at } \mathrm{C}_{3}, \mathrm{C}_{5}\right) \text {. }\end{array}$ \\
\hline $\mathbf{X}_{9}$ & $\begin{array}{l}\mathrm{IR} \\
{ }^{1} \mathrm{HNMR} \\
\left(\mathrm{CDCl}_{3}\right)\end{array}$ & $\begin{array}{l}1662(\mathrm{CONH}), 2214(\mathrm{CN}), 3334(\mathrm{CONHPh}) . \\
2.42\left(\mathrm{~s}, 3 \mathrm{H}, \mathrm{CH}_{3} \text { at 6-position }\right), 2.15\left(\mathrm{~s}, 3 \mathrm{H}, \mathrm{CH}_{3} \text { at } 4 \text {-position }\right), 2.81(\mathrm{t}, 2 \mathrm{H} \text {, } \\
\left.\mathrm{SCH}_{2}\right), 3.61\left(\mathrm{t}, 2 \mathrm{H}, \mathrm{SCH}_{2} \mathrm{CO}\right), 6.79(\mathrm{~s}, 1 \mathrm{H}, \mathrm{CH} \text { of pyridine }), 7.10-7.49(\mathrm{~m}, \\
\left.7 \mathrm{H}, 5 \text {-aromatic protons, } \mathrm{NH} \text { and } \mathrm{CDCl}_{3}\right) \text {. }\end{array}$ \\
\hline $\mathbf{X}_{10}$ & $\begin{array}{l}{ }^{1} \mathrm{HNMR} \\
\left(\mathrm{CDCl}_{3}\right)\end{array}$ & $\begin{array}{l}2.29\left(\mathrm{~s}, 3 \mathrm{H}, \mathrm{CH}_{3} \text { at } 6 \text {-position), } 2.39\left(\mathrm{~s}, 3 \mathrm{H}, \mathrm{CH}_{3} \text { at } 4-\text { position }\right), 2.49(\mathrm{~s}, 3 \mathrm{H} \text {, }\right. \\
\left.\mathrm{CH}_{3} \text { at p-position }\right), 2.80\left(\mathrm{t}, 2 \mathrm{H}, \mathrm{SCH}_{2}-\mathrm{CH}_{2}-\mathrm{CO}\right), 3.58\left(\mathrm{t}, 2 \mathrm{H}, \mathrm{SCH}_{2}-\mathrm{CH}_{2}-\right. \\
\mathrm{CO}), 6.87(\mathrm{~s}, 1 \mathrm{H}, \mathrm{CH} \text { of pyridine }), 6.90-7.60(\mathrm{~m}, 4 \mathrm{H} \text { aromatic protons), } \\
7.73(\mathrm{~s}, 1 \mathrm{H}, \mathrm{NH}) \text {. }\end{array}$ \\
\hline$\overline{\mathbf{X}_{11}}$ & $\begin{array}{l}{ }^{1} \mathrm{HNMR} \\
\left(\mathrm{CDCl}_{3}\right)\end{array}$ & $\begin{array}{l}2.42\left(\mathrm{~s}, 3 \mathrm{H}, \mathrm{CH}_{3} \text { at 6-position), } 2.51\left(\mathrm{~s}, 3 \mathrm{H}, \mathrm{CH}_{3}, \text { at 4-position), } 2.81(\mathrm{t}, 2 \mathrm{H} \text {, }\right.\right. \\
\left.\mathrm{SCH}_{2} \mathrm{CH}_{2}\right), 3.61\left(\mathrm{t}, 2 \mathrm{H}, \mathrm{SCH}_{2} \mathrm{CH}_{2} \mathrm{CO}\right), 6.79(\mathrm{~s}, 1 \mathrm{H}, \mathrm{CH} \text { of pyridine }), 7.14- \\
7.27\left(\mathrm{~m}, 6 \mathrm{H}, 4 \text {-aromatic protons, } \mathrm{NH} \text { and } \mathrm{CDCl}_{3}\right) \text {. }\end{array}$ \\
\hline $\mathbf{X}_{12}$ & $\begin{array}{l}{ }^{1} \mathrm{HNMR} \\
\left(\mathrm{CDCl}_{3}\right)\end{array}$ & $\begin{array}{l}2.42\left(\mathrm{~s}, 3 \mathrm{H}, \mathrm{CH}_{3} \text {, at } 6 \text { position), } 2.47\left(\mathrm{~s}, 3 \mathrm{H}, \mathrm{CH}_{3} \text { at } 4 \text { position }\right), 2.88(\mathrm{t}, 2 \mathrm{H} \text {, }\right. \\
\left.\mathrm{SCH}_{2} \mathrm{CH}_{2}\right), 3.59\left(\mathrm{t}, 2 \mathrm{H},-\mathrm{SCH}_{2} \mathrm{CH}_{2}-\mathrm{CO}\right), 6.80(\mathrm{~s}, 1 \mathrm{H}, \mathrm{CH} \text { of pyridine }), 7.10- \\
7.35(\mathrm{~m}, 3 \mathrm{H} \text {, aromatic protons at } 3,4 \text { and } 5 \text {-positions }), 7.77(\mathrm{~s}, 1 \mathrm{H}, \mathrm{NH}) \text {. }\end{array}$ \\
\hline
\end{tabular}


absorption, $2220 \mathrm{~cm}^{-1}$ for $\mathrm{CN}$ and at 1671-1661 $\mathrm{cm}^{-1}$ for carbonyl absorption. Reaction of 3cyano-4,6-dimethylpyridine IV with $\mathrm{POCl}_{3}$ on water-bath gave 2-chloro-3-cyano-4,6dimethylpyridine VII. The latter upon reaction with thiourea in ethanol for $3 \mathrm{hr}$. afforded the expected, 3-cyano-4,6-dimethylpyridine-2thione VIII. The mass spectrum of this compound is characterized by the appearance of molecular ion peak $\left(\mathrm{M}^{+}\right)$at 164 , the ${ }^{1} \mathrm{HNMR}$ showed singlet aromatic proton of pyridine at $\delta$ $6.69 \mathrm{ppm}$, the SH proton appear singlet at $\delta$ $13.80 \mathrm{ppm}$. Compound VIII when reacted with alcoholic $\mathrm{KOH}$ afforded the potassium salt IX, which when allowed to reacted with $\alpha$ chloroacetyl and $\beta$-chloropropionyl derivatives of some aromatic amines gave the expected thioethers,3-cyano-4,6-dimethyl-2-(substitutedthio) pyridines $\mathbf{X}_{1-12}$. The IR spectra of these compounds showed the $\mathrm{CN}$ absorption at 2221 $\mathrm{cm}^{-1}$ and the $\mathrm{NH}$ absorption at $3320-3270 \mathrm{~cm}^{-1}$, 1643-1594 $\mathrm{cm}^{-1}$ for carbonyl absorption. ${ }^{1}$ HNMR spectra of $\mathrm{X}$ showed the methylene group $\mathrm{SCH}_{2} \mathrm{CO}$ - desheileded at $\delta$ 7.00-7.20 ppm and the pyridine proton at $\delta$ 6.78-7.15 ppm.

\section{Anti-hyperlipidemic effect \\ Induction of hyperlipidemia}

Hyperlipidemia can be induced by three times weekly administration by gavage of 10 $\mathrm{ml} / \mathrm{kg}$ body weight for two weeks of a cocktail containing in $1 \mathrm{~L}$ peanut oil: $100 \mathrm{gm}$ cholesterol, $30 \mathrm{~g}$ propylthiouracil and $100 \mathrm{~g}$ cholic acid. ${ }^{11}$ Rats were maintained at constant environmental condition throughout the whole experimental period.

\section{Design of the experimental work}

Thirty six of adult male rats, weighing 120-140 g, were divided into six groups (6 rats for each). The first group served as control group. The second group served as model group. The remaining groups from 3-6 were given an oral doses of the hyperlipidemic cocktail by gavage of $10 \mathrm{ml} / \mathrm{kg}$ body weight 3 times weekly for two weeks perior to the tested compounds ( $\mathbf{I I I}_{\mathbf{2}}, \mathbf{V}_{\mathbf{4}}, \mathbf{X}_{\mathbf{1}}$ and $\mathbf{X}_{\mathbf{1 2}}$ ) then blood samples of all groups were taken from the orbital fissures of the eye by using heparanized capillary tubes. After clotting of the blood, the samples were centrifuged for $15 \mathrm{~min}$. at 3000 $\mathrm{rpm}$. The above serum layer was decanted in other epindorf tubes and subjected for estimation of lipid profil (cholestyol, triglyceride HDL and LDL) using enzymatic kits methods. For total cholesterol CHOD-PAP. (SPINREACT), SPAIN. For triglyceride (GPOPOD. Ensimatica colorimetica) (SPINREACT) SPAIN, for HDL precipitant PEG 6000 (DasaRagister), Roma.

Table 5: Effect of the synthesized compounds $\mathrm{III}_{2}, \mathbf{V}_{4}, \mathbf{X}_{1}$ and $\mathbf{X}_{12}$ on the hyperlipideamic rats.

\begin{tabular}{|l|c|c|c|c|c|c||}
\hline \multicolumn{1}{|c|}{$\begin{array}{c}\text { Group } \\
\text { Lipids }\end{array}$} & Control & $\begin{array}{c}\text { Model } \\
(\text { Cocktail) }\end{array}$ & $\begin{array}{c}\text { Compound } \\
\mathbf{I I I}_{\mathbf{2}}\end{array}$ & $\begin{array}{c}\text { Compound } \\
\mathbf{V}_{\mathbf{4}}\end{array}$ & $\begin{array}{c}\text { Compound } \\
\mathbf{X}_{\mathbf{1}}\end{array}$ & $\begin{array}{c}\text { Compound } \\
\mathbf{X}_{\mathbf{1 2}}\end{array}$ \\
\hline $\begin{array}{l}\text { Total } \\
\text { cholesterol }\end{array}$ & $58.3 \pm 2.4$ & $0.155 \pm 14.0^{\mathrm{a}}$ & $75.6 \pm 8.1^{\mathrm{b}}$ & $71.9 \pm 4.2^{\mathrm{b}}$ & $71.1 \pm 3.8^{\mathrm{b}}$ & $63.5 \pm 0.9^{\mathrm{b}}$ \\
\hline $\begin{array}{l}\text { Trigly- } \\
\text { ceride }\end{array}$ & $9.21 \pm 2.4$ & $82.6 \pm 3.2^{\mathrm{a}}$ & $47.7 \pm 5.5^{\mathrm{ab}}$ & $54.5 \pm 1.2^{\mathrm{ab}}$ & $45.5 \pm 1.5^{\mathrm{ab}}$ & $63.3 \pm 2.6^{\mathrm{ab}}$ \\
\hline HDL & $8.42 \pm 2.0$ & $31.7 \pm 2.6^{\mathrm{a}}$ & $35.6 \pm 4.6^{\mathrm{a}}$ & $26.9 \pm 2.5^{\mathrm{a}}$ & $29.4 \pm 1.7^{\mathrm{a}}$ & $28.2 \pm 1.7^{\mathrm{a}}$ \\
\hline LDL & $10.1 \pm 2.6$ & $100.8 \pm 17.4^{\mathrm{a}}$ & $30.5 \pm 8.3^{\mathrm{b}}$ & $34.0 \pm 5.8^{\mathrm{b}}$ & $32.6 \pm 4.3^{\mathrm{b}}$ & $29.3 \pm 2.6^{\mathrm{b}}$ \\
\hline
\end{tabular}

Data are presented as $\mathrm{M} \pm \mathrm{SEM}$

a: Significant from control

b: Significant from model

Statistical analysis was done using one way ANOVA followed by Tukey-Kramer as post ANOVA test. 


\section{Description of results}

Oral administration of hyperlipidemic cocktail to rats significantly increased the total cholesterol level by 265\% compared with control group (Table 5, Fig 1). Oral administration of new synthesized hypolipidemic compounds $\mathbf{I I I}_{\mathbf{2}}, \mathbf{V}_{\mathbf{4}}, \mathbf{X}_{\mathbf{1}}$ and $\mathbf{X}_{\mathbf{1 2}}$. structurally related to Niacin (hypolipidemic agent) in a dose level of $400 \mathrm{mg} / \mathrm{kg}$ body weight daily for 7 days, significantly lowered the total cholesterol level by $49 \%, 46 \%, 46 \%$ and $41 \%$ respectively compared with the model group (Table 5, Fig. 1).

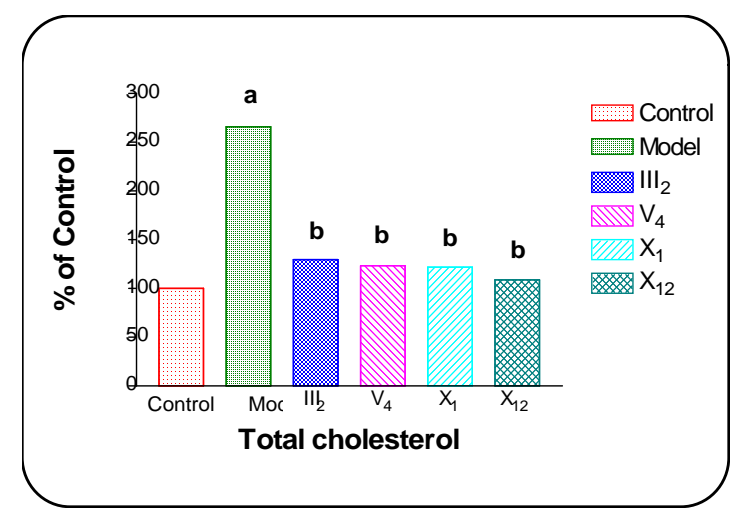

Fig. 1: Effect of some synthesized compounds on serum total cholesterol level.

Data were presented as mean \pm SEM.

a: Significant from control.

b: Significant from model.

Concerning the triglyceride level, oral administration of the hyperlipidimic cocktail to rats significantly increased the serum triglyceride by $377 \%$ compared with control group. Oral injection of compounds $\left(\mathbf{I I I}_{2}, \mathbf{V}_{\mathbf{4}}\right.$, $\mathbf{X}_{\mathbf{1}}$ and $\mathbf{X}_{\mathbf{1 2}}$ ) significantly decreased serum triglyceride by $58 \%, 66 \%, 55 \%$ and $44 \%$ compared with the model group (Table 5, Fig. 2).

Also the serum HDL was increased by hyperlipidemic cocktail by $74 \%$ compared with control group. The previous compounds have no effect on HDL level compared with the model (Table 5, Fig. 3).

Similarly, the serum level of LDL was significantly increased by $100 \%$ compared with control group. Oral injection of compounds $\left(\mathrm{III}_{2}, \mathrm{~V}_{4}, \mathrm{X}_{1}\right.$ and $\left.\mathrm{X}_{12}\right)$ significantly decreased the serum LDL by $31 \%, 34 \%, 33 \%$ and $29 \%$ respectively compared with the model group but still higher than the normal control group (Table 5, Fig. 4).

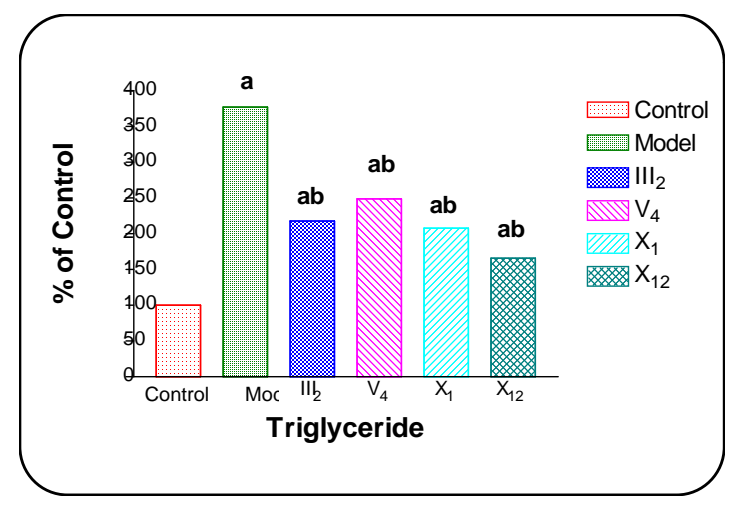

Fig. 2: Effect of some synthesized compounds on serum Triglyceride level.

Data were presented as mean \pm SEM.

a: Significant from control.

b: Significant from model.

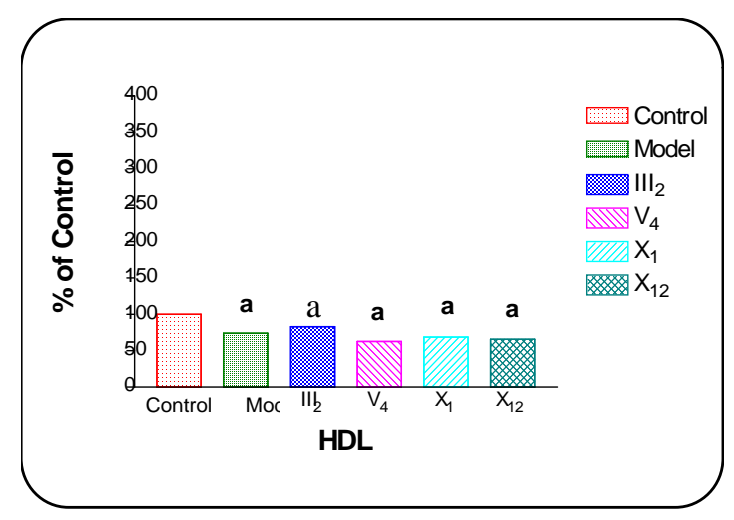

Fig. 3: Effect of some synthesized compounds on serum HDL level.

Data were presented as mean \pm SEM.

a: Significant from control.

b: Significant from model.

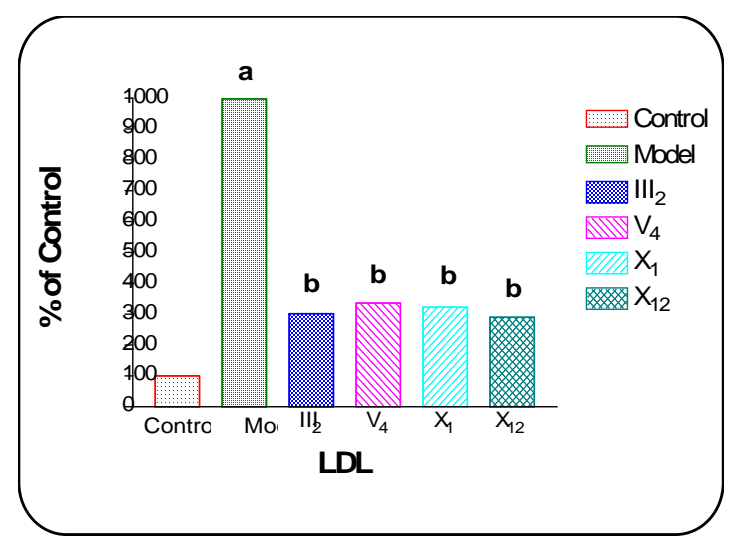

Fig. 4: Effect of some synthesized compounds on serum LDL level.

Data were presented as mean \pm SEM.

a: Significant from control.

b: Significant from model. 


\section{Discussion of antihyperlipidemic results}

The new synthesized hypolipidimic compounds in this study had been found to decrease the serum levels of cholesterol, triglyceride, HDL and LDL. This results are in the same direction with the study of Tapan et al. ${ }^{12}$ who reported that niacin in a dose level of $400-4000 \mathrm{mg} / \mathrm{kg}$ has been found to lower blood lipid. The mechanism underlying the cocktail induced-hyperlipideamia may be due to thiouracil contained in this cocktail has antithyroid effect, this leads to sensetization of blood vessels to the effect of adrenaline. ${ }^{12}$ The mechanism underlying the synthetic compounds lowering blood levels of cholesterol, triglyceride HDL and LDL may be due to increase steroid excretion and inhibition of cholesterol synthesis from active acitate. ${ }^{13,14}$ In addition, nicotinic acid revealed significant antilipolytic effect by inhibiting the release of NEFA and glycerol from adipose tissues and decrease the synthesis and release of VLDL TG from liver. ${ }^{15}$ Because our new synthesized compounds ( $\mathbf{I I I}_{\mathbf{2}}, \mathbf{V}_{\mathbf{4}}, \mathbf{X}_{\mathbf{1}}$ and $\mathbf{X}_{\mathbf{1 2}}$ ) have structuraly similarity to nicotinic acid we suggest that these compound lower blood lipid profil may be throughout the above mechanisms.

\section{Conclusion}

The new synthesized compounds $\left(\mathbf{I I I}_{\mathbf{2}}, \mathbf{V}_{\mathbf{4}}\right.$, $\mathbf{X}_{\mathbf{1}}$ and $\mathbf{X}_{12}$ ) have marked lowering effects on serum cholesterol, triglyceride, HDL and LDL. Moreover they have the same relative potency in this manner.

\section{REFERENCES}

1- J. B. John, C. L. William, F. L. George, S. P. Gerald, W. R. Andrew, L. E. Edward and H. Ralph, J. Med. Chem., 22 (11), 1284-1987 (1979).
2- J. B. John, L. E. Edward, H. Ralph, S. P. Gerald, G. A. Joseph, K. W. Burton, S. S. Charles and S. Alexander, J. Med. Chem., 23, 65-70 (1980).

3- E. M. David, J. B. John, C. R. William, F. L. Thomas, K. Mesler, G. F. Lundell, A. W. Raad, G. E. Dennis, A. R. Dwin, S. S. Charles and W. Michoel, J. Med. Chem., 26, 649-657 (1983).

4- A. N. Osman, M. M. Ismail and M. A. Barakat, Egypt. J. Pharm. Sci., 28, (1-4) 87-98 (1987).

5- J. L. Simonsen and M. Nayak, J. Chem. Soc., 107, 792-8 (1915).

6- A. N. Osman, M. A. Shaban, Mohsen M. Ismail and A. A. El-Gendy, Bull Fac. Pharm. Cairo, Univ., 28, 2, 25-28 (1990).

7- Mohsen M. Ismail and K. M. Ghoneim, Bull. Fac. Pharm. Cairo, Univ., 32 (2), 171-175, (1994).

8- G. Karl and J. Hans, Ger (East) 107, 287 (Cl.C 07d) 20 Jul.,1974, Appl. 172 688,01 Aug (1973).??

9- H. Jahine, H. A. Zaher, A. A. Sayed and M. J. F. Seada, Prakt. Chemie, 316, 2, 337-343 (1974).

10- S. El-Mogahazy, Egypt. J. Pharm. Sci., 33, (3-4), 527-538 (1992).

11- L. C. Fillios, Andrus Stb, G. V. Mann and F. J. Stare, J. Exper. Med., 104, 539 (1956).

12- K. Tapan, Basu and Sarabjit Mann, J. Nutr. 127 (1), 117-121 (1997).

13- S. M. Grundy, H. Y. I. Mok, L. Zech, M. Berman, J. Lipid Res., 22, 24-26 (1981).

14- L. Kaijser, B. Eklund, A. G. Olson and L. A. Carlson, Med. Biol., 57, 114-117 (1979).

15- G. P. Ellis and G. B. West, "Progress in Medicinal Chemistry 11", North-Holland, Publishing company Amsterdam oxford, 1975, p. 124. 